\title{
COVID-19: The New Threat
}

\author{
Shaila Rahman ${ }^{1,{ }^{*}}$ and Tamanna Bahar ${ }^{2}$ \\ ${ }^{1}$ Department of Medicine, Shahabuddin Medical College and Hospital, Dhaka, Bangladesh \\ ${ }^{2}$ Department of Haematology, National Institute of Cancer Research and Hospital, Dhaka, Bangladesh \\ "Corresponding author: Department of Medicine, Shahabuddin Medical College and Hospital, Dhaka, Bangladesh. Tel: +880-1816643167, Email: shailars43@gmail.com
}

Received 2020 February 25; Revised 2020 March 04; Accepted 2020 March 04.

\begin{abstract}
In December 2019 the world has come to know a new coronavirus disease named COVID-19. It has affected mainland China mostly and has spread to all continents of the world except Antarctica. Patients mostly have come with a flu-like illness and non-specific gastrointestinal symptoms to a lesser extent. In most cases, home isolation is effective. However, cases of moderate to severe pneumonia and acute respiratory distress syndrome (ARDS) require hospitalization and few cases need mechanical ventilation. Older adults with a pre-existing medical illness suffer more. Different newer molecular techniques are developed to confirm the diagnosis. Currently, there is no existing treatment and vaccine. Different anti-microbials are on trial. Infection prevention practice is the best for now. With its highly contagious nature and increasing panic among nations, the world is waiting for definitive newer treatment options and a potential vaccine. This narrative review has compiled the updated information about COVID-19 in the hope that it will be helpful to the medical professionals in their knowledge and be prepared for the outbreak of a pandemic.
\end{abstract}

Keywords: COVID-19, SARS-CoV-2, ARDS, Pandemic

\section{Context}

Different emerging and re-emerging viral infections have attacked different countries at different periods. Some are benign, whereas some are deadly with versatile clinical presentations. The involvement of the respiratory system may range from common cold to severe acute respiratory illness (SARI). The outbreak of severe acute respiratory syndrome (SARS) (1) and Middle-East respiratory syndrome (MERS) (2) in the year 2002 - 3 and 2012 respectively have caused deadly illness. In December 2019 the world is introduced to a novel coronavirus severe acute respiratory syndrome coronavirus 2 (SARS-CoV-2; formerly called 2019-nCoV) causing coronavirus disease 2019 (COVID-19) after the outbreak of pneumonia in Wuhan, a city in Hubei Province of China (3). Initial clusters of pneumonia of unknown origin were reported to WHO on December 31, 2019. The WHO declared the COVID-19 outbreak a Global Health Emergency on January 30, $2020(4,5)$. Later on, WHO has declared it a pandemic on March 11 (6).

Covid-19 has spread from China to other parts of the world affecting 143 countries (7). Outside China, Thailand was the first country to report the confirmed case of COVID19 (8) and the Philippines, reported the first death (9). To date WHO has reported 153517 confirmed cases (10 982 new) globally of which China has comprised 81048 confirmed cases (27 new). A total of 3204 deaths (10 new) are reported in China and 2531 deaths (333 new) are reported outside. The outbreak has spread quickly and seriously to the new epicentre Italy (confirmed cases $=21157$, deaths $=1441$ ), Republic of South Korea (confirmed cases $=8162$, deaths $=75$ ), Iran (confirmed cases $=12729$, deaths $=608$ ), japan (confirmed cases $=780$, deaths $=22$ ), France $($ confirmed cases $=$ 4469 , death $=91$ ), Germany (confirmed cases $=3795$, death $=8$ ), Spain (confirmed cases $=5753$, death $=136$ ), Singapore (confirmed cases $=2120$, the United States (confirmed cases $=1678$, death $=41)$, Kuwait $($ confirmed cases $=112)$, Bahrain (confirmed cases $=211$ ), Thailand (confirmed cases $=75$, death $=1$ ), the United Kingdom (confirmed cases = 1144 , deaths $=21$ ), Australia (confirmed cases $=249$, death $=3$ ), Canada (confirmed cases $=244$, death $=1$ ), and Saudi Arabia (confirmed cases $=103$ ). The death rate is highest in Italy (6.8\%). The increasing COVID-19 cases in the Eastern Mediterranean region is also of great concern. In Iran the fatality rate is about $4.8 \%$ of total confirmed cases. Nine new countries/areas Kazakhstan, Curaçao, Namibia, Central African Republic, Congo, Equatorial Guinea, Eswatini, Mauritania, and Mayotte have reported cases of COVID-19 in past 24 hours (7).

The pandemic of COVID-19 is explained by the high con-

Copyright (c) 2020, International Journal of Infection. This is an open-access article distributed under the terms of the Creative Commons Attribution-NonCommercial 4.0 International License (http://creativecommons.org/licenses/by-nc/4.0/) which permits copy and redistribute the material just in noncommercial usages, provided the original work is properly cited. 
tagiousness of SARS-CoV-2 as expressed by the high basic reproductive number $\left(R_{0}\right)$ of $2-2.5$. It needs to be less than one to reduce the spread of infection (10).

\section{The Characteristics of SARS-CoV-2 and it's Pathogen- esis}

SARS-CoV-2 is a novel group $2 \mathrm{~b}$ beta-coronavirus of the subgenus sarbecovirus, Orthocoronaviridae subfamilies. It has at least $70 \%$ similarity in genetic sequence to SARS$\mathrm{COV}$ (11). Some coronaviruses specially SARS-CoV and MERS$\mathrm{CoV}$ are zoonotic viruses that are causing respiratory illness in humans (12). Bat is thought to be the vector as different coronaviral diseases including SARS and MERS were related to that. The initial cases of SARS-CoV-2 are thought to be related to the illegal selling of animals in the wet seafood market in Huanan. Later on, cases of humanhuman transmission were reported on a large scale (13).

The case fatality for SARS-CoV and MERS-CoV was $10 \%$ (total affected more than 8000) and 34.5\% (total affected cases were 2465) respectively. Though the case fatality of COVID-19 is $2.3 \%$ (14), the increasing number of cases is a concern now (Figure 1).

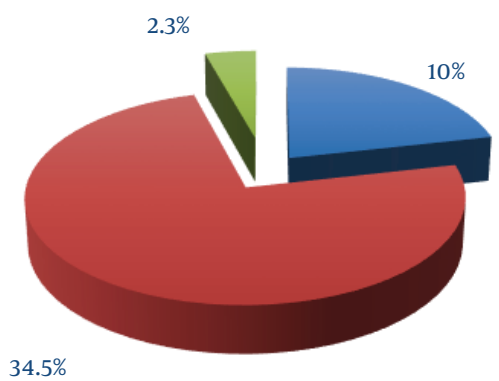

SARS

MERS

COVID-19

Figure 1. Fatality rate of SARS, MERS, and COVID-19

COVID-19 can affect any age group. Most of the cases (77.8\%) were in 30 - 69 years age group. Pre-existing hypertension, diabetes, cardiovascular, cancer, and chronic respiratory illness are at risk of complications with a little male predominance $(51.4 \%)(14,15)$.

SARS-CoV-2 spreads by respiratory droplets. It is infectious when comes to contact with the mucous membrane. The exact survival of it in the environment is unknown. Though considering characteristics of SARS-CoV and MERS$\mathrm{CoV}$, it may survive on a surface for hours to days at room temperature (average $20^{\circ} \mathrm{C}$ ) and with high humidity (16).
It can be killed by soap wash and disinfectants such as $75 \%$ alcohol. The incubation period is two days to 14 days. Initially, asymptomatic carriers were thought to be noncontagious. Later on in China, a cluster of cases in a family was reported to be contracted from an asymptomatic carrier who recently traveled from Wuhan (17). Traveling history to the affected area such as China especially Wuhan, the Republic of Korea, Italy, Iran, Japan, Singapore, France, Germany, Spain, the United States of America, Thailand, the United Kingdom, and so on within 14 days of symptom onset is crucial to diagnose COVID-19 $(7,18,19)$.

\section{Clinical Manifestations of COVID-19}

Respiratory illness presents as a flu like illness. Fever, cough, myalgia, and fatigue are the commonest symptoms. Other features include dyspnea, headache, malaise, non-specific gastrointestinal (GI) symptoms such as abdominal pain, nausea, diarrhea. The GI symptoms are thought to be due to the binding of virus glycoprotein to intestinal angiotensin-converting enzyme (ACE2) receptors (20). The WHO has set definitions for identification of cases (Table 1) (19). As China is the epicentre of the outbreak, the laboratory-confirmed cases along with all the suspected and clinically diagnosed cases are included in the report so the total number has jumped high (21).

Wang et al. showed in a study of 138 patients that it took about two days from admission to develop dyspnea, then two to three days for needing intensive care unit admission (ICU). The Median Hospital stay was 10 days (Figure 2) (15). This study is supported by Huang et al. (22).

COVID-19 may range from asymptomatic and mild illness to severe illness. Most of the patients have an uncomplicated illness, mild to moderate pneumonia. Few patients have a severe acute respiratory illness (SARI) which includes severe pneumonia, ARDS, sepsis, and septic shock (21). China CDC has published data on COVID-19 which showed $80.9 \%$ cases were mild. Severe illness and critical cases were $13.8 \%$ and $4.7 \%$ respectively (Figure 3) (23).

Critical illness included respiratory failure, septic shock, and multi-organ failure. The majority of the death was observed $\geq 60$ years of age and/ or who had preexisting, comorbid conditions such as hypertension, cardiovascular disease, and diabetes. The case fatality rate is highest among critical cases at 49\%. Among the comorbid conditions, cardiovascular disease was higher (10.5\%). The healthcare workers (HCW) were also affected (3.8\%) and fatality was $0.5 \%$ (23). 


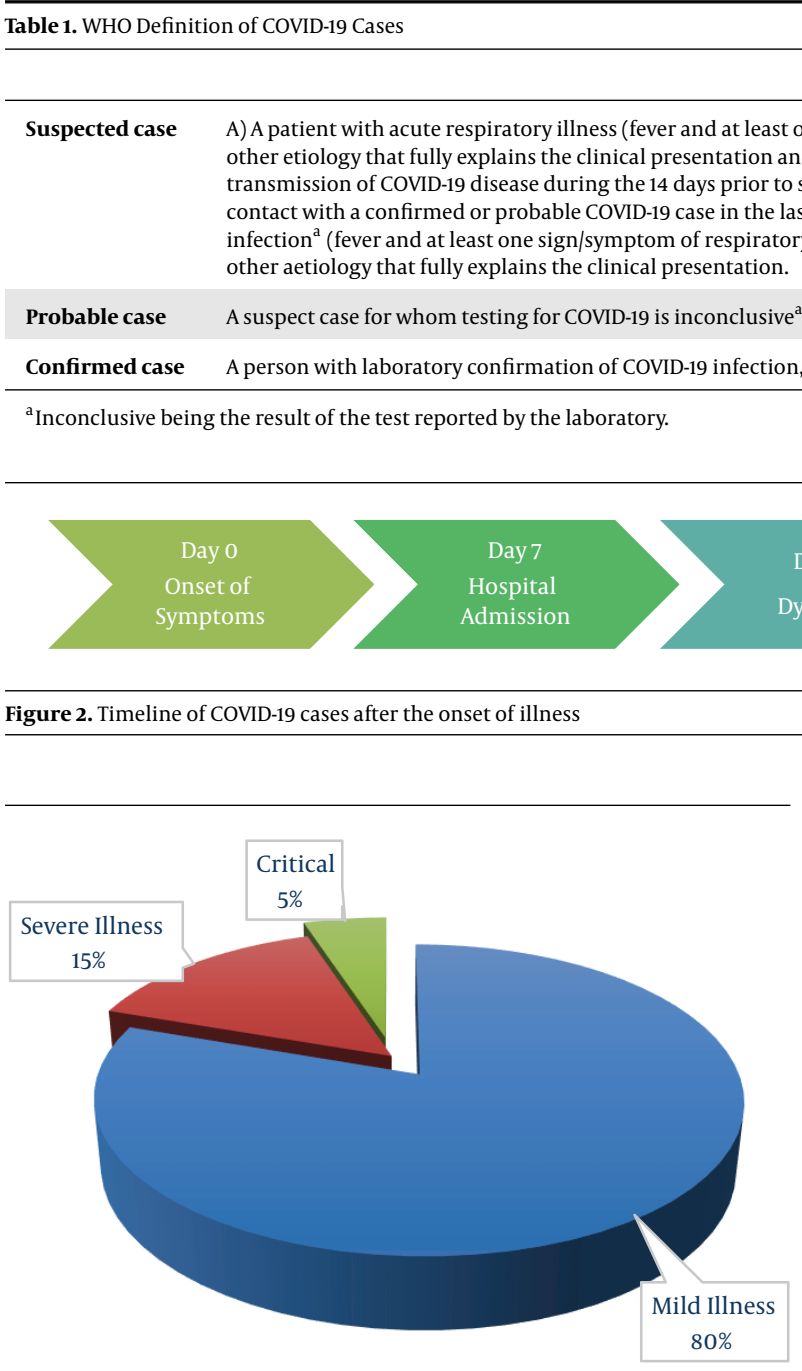

Figure 3. The extent of illness in COVID-19

\section{Pregnancy, Lactation, and COVID-19}

No case of vertical transmission is proven yet. Chen et al. (24) showed in a study that the fetal outcome was good. The study was conducted on a small sample of patients in the third trimester who had undergone a caesarian section. Therefore, the possibility of transmission of SARSCoV-2 in the first and second trimester is yet to be ruled out. Pregnant women with suspected or confirmed 2019-nCoV infection should get supportive treatment taking into account the physiologic adaptations of pregnancy. The use of investigational therapeutic agents outside of a research study should be carefully guided by individual risk-benefit analysis based on potential benefits for mother and safety to the fetus. The consultation with an obstetric specialist

\section{Definition}

Day 8

Dyspnea

Day 9

ARDS

Day 10

ICU

Admission and Ethics Committee is essential. The decision for emergency delivery and pregnancy termination is challenging. Gestational age, maternal condition, and fetal stability are to be taken into account and consultations with obstetric, neonatal, and intensive care specialists (depending on the condition of the mother) are essential (21).

Breastfeeding is very beneficial for the development of the baby. Mothers with confirmed COVID-19 or symptomatic patients under investigation (PUI) can feed their babies with proper hand hygiene and wearing protective masks. If expressed milk is collected manually or by an electric pump, then washing hands before touching the bottle or parts is essential. It is advised to feed the expressed milk to the baby by a dedicated carer (25).

\section{Diagnosis of COVID-19}

Early diagnosis, isolation, and prompt treatment is the key to success in COVID-19. Currently real-time reverse transcription-polymerase chain reaction (rRT-PCR) based technique is used to confirm the cases (21). The respiratory specimen preferably from the lower respiratory tract (sputum, bronchoalveolar lavage, bronchial aspirate) is used for higher yield. Upper respiratory specimen (nasopharyngeal) is also used to detect SARS-CoV-2. A newer kit is developed to detect serum immunoglobulin in suspected cases which can give results in 15 minutes. Chest X-ray showing bilateral infiltrates and in computed tomography (CT) chest ground-glass opacities are said to be characteristic. In China, the chest X-ray and CT scan of the chest with characteristic findings are also included as cases $(21,23)$. 
Ai et al. (26) showed in a study that CT had a higher sensitivity for the diagnosis of COVID-19 as compared with initial reverse-transcription polymerase chain reaction (RTPCR) from swab samples in the initial epidemic area of China. The positive rates of RT-PCR assay and chest CT imaging in the cohort were 59\% (601/1014), and 88\% (888/1014) for the diagnosis of suspected patients with COVID-19, respectively. With RT-PCR as a reference, the sensitivity of chest CT imaging for COVID-19 was 97\% (580/601). In patients with negative RT-PCR results but positive chest CT scans ( $\mathrm{n}=308$ patients), 48\% (147/308) of patients were re-considered as highly likely cases, with $33 \%$ (103/308) as probable cases by a comprehensive evaluation. With the analysis of serial RT-PCR assays and CT scans, $60 \%$ to $93 \%$ of patients had initial positive chest CT consistent with COVID-19 before the initial positive RT-PCR results. $42 \%$ of patients showed improvement of follow-up chest CT scans before the RT-PCR results in turning negative (26).

The presence of SARS-CoV-2 RNA in feces is identified in a case in the USA (27).

Other investigations to rule out the differential diagnosis of flu and bacterial pneumonia need to be carried out. The extent of organ damage can be ascertained by checking renal function, sepsis markers and assessing the comorbidities $(21,23)$.

\section{Treatment}

The treatment is mainly supportive. Ideally, all patients should be treated in the hospital. However, due to a shortage of beds and resources, uncomplicated mild cases may be treated at home isolation with minimum contact of a few caregivers preferably one-one with the practice of hand hygiene and using masks. The caregiver should be a healthy individual without any immunosuppression. The room should be well ventilated with windows open. A minimum of one-meter space should be maintained (28).

Patients with SARI require vital organ support. Antibiotics need to be started if secondary bacterial infection is suspected after sending an appropriate sample for culture. The role of steroids is controversial as it delayed viral clearance. ICU admission is necessary if critically ill (21). Favilavir, first anti-viral got approval for marketing in COVID19 pneumonia (clinical trial ongoing; showed efficacy in human trial). Remdesivir and Chloroquine are found to be effective in vitro shown by Wang et al. (29) A randomized control trial of remdesivir is started on 761 patients in Wuhan. Newer therapies like brilacidin, leronlimab (PRO 140), a CCR5 antagonist and neutralizing monoclonal antibodies are being tested along with trials of different other antivirals like ritonavir, lopinavir, oseltamivir (21). Plasma from recovered patients is being used to treat patients with a light of hope (30).

\section{Prognosis}

Prognosis is good, especially no death occurred except in critically ill. It took about 10 days on average for recovery (15). Two respiratory samples taken 24 hours apart must be negative during the recovery phase prior to discharging a patient (21).

Recently few confirmed COVID-19 cases (HCWs) tested positive again by rRT-PCR after hospital discharge. They were tested positive after $5-13$ days of discharge during the home quarantine. However, they were asymptomatic and chest CT did not show any change from previous images (31).

\section{Preventive Measures}

For now, prevention is the best approach to stop the spread of infection. China has tried best to contain the infection by restricting travel though WHO is not recommending such containment (23). Rather WHO has strongly recommended hand and respiratory hygiene for cases, contacts, carer, and HCWs $(28,32)$.

The hand hygiene involves using alcohol-based hand rubs before and after each patient contact. Washing hands with soap-water for 20 seconds is also effective. If hands are visibly soiled then cleaning with soap-water is recommended. A disposable paper towel should be used to dry hands then. If it is not available then clean cloth can be used and wet ones should be replaced. It is also recommended to follow hand hygiene before and after preparing food, before eating, before and after removing gloves and masks, and after using the toilet. Separate reusable utensils can be used by the patient after proper cleaning.

Disinfecting the immediate environment of the patient including toilet and furniture with $0.5 \%$ sodium hypochlorite is beneficial (28).

Maintaining cough etiquette such as using tissue during cough or sneeze and discarding in a closed bin. If tissue is not available then cough or sneeze in a flexed elbow. A clean cloth can be used instead of tissue and washed with soap water to reuse. Avoiding handshaking is also advised for the time being. Clean and disinfect bathroom and toilet surfaces at least once daily. Regular household soap or detergent should be used first for cleaning, and then, after rinsing, regular household disinfectant containing $0.5 \%$ sodium hypochlorite should be applied (28). 
The medical mask is not recommended for healthy people unless it is a cultural practice (33). Patients and the caregivers including HCWs are advised to wear masks. It is recommended to remove the mask from behind and practicing hand hygiene thereafter (28).

At home isolation, both the patients and caregivers should wear masks and follow respiratory and hand hygiene (28).

The HCWs are especially advised to wear personal protective equipment (PPE) including N95 respirator masks and eye shield while taking respiratory samples (21). Avoiding contact with body fluids is essential. Dedicated medical equipment such as stethoscopes, blood pressure cuffs, and thermometers should be kept for individual patients. If equipment needs to be shared among patients, cleaning and disinfecting it between use for each individual patient by using ethyl alcohol 70\% is recommended (32).

Contact tracing and quarantine of immediate contact (direct carer without PPE, family members, classmates, travelers sitting within one-meter distance) of a confirmed COVID-19 are recommended with dignity. The duration is 14 days from the last contact with confirmed COVID-19 case. Contacts should practice hand and respiratory hygiene. They should be checked daily for fever and other symptoms suggestive of COVID-19 (34).

The development of a vaccine is on the horizon and the world is looking forward eagerly.

\section{Care and Disposal of Corpse}

The PPE must be worn by the handler of the deceased body (hospital staff). The body has to be wrapped in white cotton linen followed by two layers of body bag. The outer most layer with disinfectant ( $0.5 \%$ sodium hypochlorite). Relatives should not touch the body and sealed coffins are not to be opened. Incarceration or burial should be done with dignity without making any delay. If suspected case dies then, a postmortem must be carried out ensuring the earliest appropriate disposal of the body (35).

\section{Conclusions}

As SARS-CoV-2 COVID-19 pandemic has created panic worldwide, more research is needed to evaluate the nature of the disease. For resource-poor health-care services tackling the outbreak will be difficult. So prior preparation for the outbreak is necessary. The HCWs are at the utmost risk. So precautions and training of all the HCWs are important.

\section{Footnotes}

Authors' Contribution: Shaila Rahman did literature search and manuscript preparation. Tamanna Bahar did literature search and critical appraisal of manuscript

Conflict of Interests: None.

Funding/Support: None.

\section{References}

1. Centers for Disease Control and Prevention. Frequently asked questions about SARS. 2005. Available from: https://www.cdc.gov/sars/about/ faq.html.

2. World Health Organization. Middle East respiratory syndrome coronavirus (MERS-CoV). 2019. Available from: https://www.who.int/ emergencies/mers-cov/en.

3. CDC. Novel coronavirus, Wuhan, China. 2019, [cited 2020 Feb 23]. Available from: https://www.cdc.gov/coronavirus/2019ncov/about/index.html.

4. Gallegos A. WHO declares public health emergency for novel coronavirus. Medscape Medical News. 2020, [cited 2020 Feb 23]. Available from: https://www.medscape.com/viewarticle/924596.

5. Ramzy A, McNeil DG. W.H.O. Declares global emergency as Wuhan coronavirus spreads. The New York Times. 2020, [cited 2020 Feb 23]. Available from: https://nyti.ms/2RER70M.

6. World Health Organization. WHO Director-General's opening remarks at the media briefing on COVID-19 - 11 March 2020. 2020, [cited 2020 Mar 17]. Available from: https://www.who.int/dg/speeches/detail/whodirector-general-s-opening-remarks-at-the-media-briefing-oncovid-19---11-march-2020.

7. World Health Organization. Coronavirus disease 2019 (COVID-19) situation report - 55. 2020, [cited 2020 Mar 17]. Available from: https://www.who.int/docs/default-source/coronaviruse/situationreports/20200315-sitrep-55-covid-19.pdf?sfvrsn=33daa5cb_8.

8. World Health Organization. Novel coronavirus (2019-nCoV) situation report - 1. 2020, [cited 2020 Jan 21]. Available from: https://www.who.int/docs/default-source/coronaviruse/situationreports/20200121-sitrep-1-2019-ncov.pdf?sfvrsn=20a99c10_4.

9. World Health Organization. Novel coronavirus(2019-nCoV) situation report - 13. 2020, [cited 2020 Mar 4]. Available from: https://www.who.int/docs/default-source/coronaviruse/situationreports/20200202-sitrep-13-ncov-v3.pdf?sfvrsn=195f4010_6.

10. World Health Organization. Report of the WHO-China joint mission on coronavirus disease 2019 (COVID-19). 2020, [cited 2020 Mar 3]. Available from: https://www.who.int/docs/default-source/coronaviruse/whochina-joint-mission-on-covid-19-final-report.pdf.

11. Hui DS, I. Azhar E, Madani TA, Ntoumi F, Kock R, Dar O, et al. The continuing 2019-nCoV epidemic threat of novel coronaviruses to global health - The latest 2019 novel coronavirus outbreak in Wuhan, China. Int J Infect Dis. 2020;91:264-6. doi: 10.1016/j.ijid.2020.01.009. [PubMed: 31953166].

12. Abutaleb Y. How the new coronavirus differs from SARS, measles and Ebola. The Washington Post. 2020, [cited 2020 Jan 27]. Available from: https://www.washingtonpost.com/health/how-the-newcoronavirus-differs-from-sars-measles-and-ebola/2020/01/23/ aac6bb06-3e1b-11ea-b90d-5652806c3b3a_story.html.

13. Chen N, Zhou M, Dong X, Qu J, Gong F, Han Y, et al. Epidemiological and clinical characteristics of 99 cases of 2019 novel coronavirus pneumonia in Wuhan, China: A descriptive study. Lancet. 2020;395(10223):507-13. doi: 10.1016/S0140-6736(20)30211-7. [PubMed: 32007143]. 
14. Otto MA. Wuhan virus: What clinicians need to know. Medscape Medical News. 2020, [cited 2020 Jan 27]. Available from: https://www. medscape.com/viewarticle/924268.

15. Wang $\mathrm{D}, \mathrm{Hu} \mathrm{B}, \mathrm{Hu} \mathrm{C}$, Zhu F, Liu X, Zhang J, et al. Clinical characteristics of 138 hospitalized patients with 2019 novel coronavirus-infected pneumonia in Wuhan, China. JAMA. 2020. doi: 10.1001/jama.2020.1585. [PubMed: 32031570]. [PubMed Central: PMC7042881].

16. ECDC. Interim guidance for environmental cleaning in non-healthcare facilities exposed to SARS-CoV-2. 2020, [cited 2020 Feb 18]. Available from: https://www.ecdc.europa.eu/en/publications-data/interimguidance-environmental-cleaning-non-healthcare-facilitiesexposed-2019.

17. Bai Y, Yao L, Wei T, Tian F, Jin DY, Chen L, et al. Presumed asymptomatic carrier transmission of COVID-19. JAMA. 2020. doi: 10.1001/jama.2020.2565. [PubMed: 32083643]. [PubMed Central: PMC7042844].

18. CDC. 2019 novel coronavirus, Wuhan, China: Interim guidance for healthcare professionals. 2020, [cited 2020 Feb 23]. Available from: https: //www.cdc.gov/coronavirus/2019-nCoV/clinical-criteria.html.

19. World Health Organization. Global surveillance for human infection with coronavirus disease (COVID-19) Interim guidance. 2020, [cited 2020 Feb 27]. Available from: https://www.who.int/publicationsdetail/global-surveillance-for-human-infection-with-novelcoronavirus-(2019-ncov).

20. Wan Y, Shang J, Graham R, Baric RS, Li F. Receptor recognition by novel coronavirus from Wuhan: An analysis based on decade-long structural studies of SARS. J Virol. 2020. doi: 10.1128/JVI.00127-20. [PubMed: 31996437].

21. World Health Organization. Clinical management of severe acute respiratory infection when novel coronavirus (2019-nCoV) infection is suspected-Interim Guidance. 2020, [cited 2020 Feb 18]. Available from: https://www.who.int/publications-detail/clinical-managementof-severe-acute-respiratory-infection-when-novel-coronavirus(ncov)-infection-is-suspected.

22. Huang C, Wang Y, Li X, Ren L, Zhao J, Hu Y, et al. Clinical features of patients infected with 2019 novel coronavirus in Wuhan, China. The Lancet. 2020;395(10223):497-506. doi:10.1016/s0140-6736(20)30183-5.

23. The Novel Coronavirus Pneumonia Emergency Response Epidemiology Team. The epidemiological characteristics of an outbreak of 2019 novel coronavirus diseases (COVID-19) - China, 2020. China CDC Wkly. 2020;41(2):145-51. doi: 10.3760/cma.j.issn.0254-6450.2020.02.003.

24. Chen H, Guo J, Wang C, Luo F, Yu X, Zhang W, et al. Clinical characteristics and intrauterine vertical transmission potential of COVID-19 infection in nine pregnant women: A retrospective review of medical records. The Lancet. 2020;395(10226):809-15. doi: 10.1016/s01406736(20)30360-3.

25. CDC. Interim guidance on breastfeeding for a mother con firmed or under investigation for COVID-19. 2020. Available from: https://www.cdc.gov/coronavirus/2019-ncov/specificgroups/pregnancy-guidance-breastfeeding.html.

26. Ai T, Yang Z, Hou H, Zhan C, Chen C, Lv W, et al. Correlation of chest CT and RT-PCR testing in coronavirus disease 2019 (COVID-19) in China: A report of 1014 cases. Radiology. 2020:200642. doi: 10.1148/radiol.2020200642. [PubMed: 32101510].

27. Holshue ML, DeBolt C, Lindquist S, Lofy KH, Wiesman J, Bruce H, et al. First case of 2019 novel coronavirus in the United States. N Engl J Med. 2020;382(10):929-36. doi: 10.1056/NEJMoa2001191. [PubMed: 32004427].

28. World Health Organization. Home care for patients with suspected novel coronavirus ( $\mathrm{nCoV}$ ) infection presenting with mild symptoms and management of contacts-Interim guidance. 2020, [cited 2020 Feb 18] Available from: www.who.int/publications-detail/home-care-forpatients-with-suspected-novel-coronavirus-(nCoV)-infectionpresenting-with-mild-symptoms-and-management-of-contacts.

29. Wang M, Cao R, Zhang L, Yang X, Liu J, Xu M, et al. Remdesivir and chloroquine effectively inhibit the recently emerged novel coronavirus (2019-nCoV) in vitro. Cell Res. 2020;30(3):269-71. doi: 10.1038/s41422-020-0282-0. [PubMed: 32020029]. [PubMed Central: PMC7054408]

30. Chen L, Xiong J, Bao L, Shi Y. Convalescent plasma as a potential therapy for COVID-19. Lancet Infect Dis. 2020. doi: 10.1016/S14733099(20)30141-9. [PubMed: 32113510].

31. Lan L, Xu D, Ye G, Xia C, Wang S, Li Y, et al. Positive RT-PCR test results in patients recovered from COVID-19. JAMA. 2020. doi 10.1001/jama.2020.2783. [PubMed: 32105304]

32. World Health Organization. Infection prevention and control during health care when novel coronavirus ( $\mathrm{nCoV}$ ) infection is suspected Interim guidance. 2020, [cited 2020 Mar 2]. Available from: https://www.who.int/publications-detail/infection-preventionand-control-during-health-care-when-novel-coronavirus-(ncov)infection-is-suspected-20200125.

33. World Health Organization. Advice on the use of masks in the community, during home care and in healthcare settings in the context of the novel coronavirus (2019-nCoV) outbreak. 2020, [cited 2020 Feb 20]. Available from: https://www.who.int/publications-detail/adviceon-the-use-of-masks-in-the-community-during-home-care-andin-healthcare-settings-in-the-context-of-the-novel-coronavirus(2019-ncov)-outbreak.

34. World Health Organization. Considerations for quarantine of individuals in the context of containment for coronavirus disease (COVID19) Interim guidance. 2020, [cited 2020 Mar 2]. Available from: https://www.who.int/internal-publications-detail/considerationsfor-quarantine-of-individuals-in-the-context-of-containment-forcoronavirus-disease-(covid-19).

35. National Institute of Forensic Medicine Malaysia. Interim Guidelines for handling dead bodies of suspected/probable/confirmed 2019 novel corona virus (2019-nCoV death). Malaysia; 2020. 